\title{
Molecular Characterization of Enterobacter and Escherichia coli Pathotypes Prevalent in the Popular Street Foods of Dhaka City and their Multidrug Resistance
}

\author{
Md. Belal Hossain ${ }^{1}$, Nur Dhakirah Binti Mahbub ${ }^{1}$, Md. Miraj Kobad Chowdhury ${ }^{2}$, Md. Mizanur Rahaman ${ }^{1 *}$ \\ ${ }^{1}$ Department of Microbiology, University of Dhaka, Dhaka-1000, Bangladesh, ${ }^{2}$ Department of Genetic Engineering and Biotechnology, University of Dhaka, \\ Dhaka-1000, Bangladesh.
}

\begin{abstract}
Food borne pathogenic enteric bacteria are of great concern for global public health. Among them, Escherichia coli and Enterobacter spp. are the most prevalent in the street food. In this study, 23 strains of such enteric bacteria were isolated from multiple food samples by conventional cultural technique. Isolated strains were characterized molecularly into different genotypes using RAPD, amplified ribosomal DNA restriction analysis, and partial sequencing of 16S rDNA. RAPD represents 10 different types of strains whereas ARDRA clusters them into two separate groups. 16 out of the 23 isolates were identified as $E$. coli and the rest were as Enterobacter spp. by biochemical tests and were further confirmed by partial 16S rDNA sequencing. Significant level of virulence traits including $s t x 1$, st $x 2$ and $e s c \mathrm{~V}$ genes were identified in $E$. coli strains. Also, most of the isolates were found resistant to azithromycin and amoxicillin. This study revealed the presence of various pathogenic enteric bacteria in various street foods with multidrug resistance. Therefore, this study suggests that people consuming such street foods are at major risk of food borne illness.
\end{abstract}

Keywords: Street food, enteric bacteria, virulence genes, multidrug resistance.

\section{Introduction}

Food is an awfully effective vehicle for the conveyance of a variety of pathogens ${ }^{1,2}$. Lack of food safety results different food borne diseases which puts a constant threat to public health ${ }^{3}$. In Bangladesh, about 30 million people suffer from food borne illnesses each year of which diarrheal diseases kill approximately 2.2 million people including many children yearly ${ }^{4}$. Over the years, food borne diseases have been considered a major public health problem considering the socio-economic status in developing countries ${ }^{5}$. Many previous reports claim that consumption of non-homemade foods, especially street foods which can easily be contaminated by foodborne pathogens, is mostly responsible for food borne diseases ${ }^{6}$. High loads of bacterial pathogens in different street foods have been reported for several times in Bangladesh. These dangerous street foods are triggering deadly diseases, especially among children. Statistical evidence indicates children younger than five are at the greatest risk ${ }^{7}$. Street food vendors have little or no knowledge about food safety and hygiene in Bangladesh ${ }^{8}$. Hence, the chance of microbial contamination can be very high in the street foods. In recent time, bacterial contamination of the street foods has drawn most of the attention not merely due to their pathogenicity but also due to their high antibiotic resistance pattern ${ }^{9}$. High prevalence of multidrug resistance genes among the street food bacterial isolates have been reported in many countries. One of the major groups of these food borne pathogens comprises of enteric bacteria, mostly Escherichia coli ${ }^{10}$. Many previous reports identified high prevalence of $E$. coli into the different street foods in Bangladesh ${ }^{11}$. E. coli is highly versatile that can frequently be deadly pathogens. Considering the overall situation of occurrence of the virulence traits among the street food, E. coli is a growing concern in Bangladesh. This study was carried out to assess the virulence potential and to categorize the food borne $E$. coli into various pathotypes along with their antibiotic resistance pattern from different street food items in Dhaka. Various virulent traits were examined to detect different pathotypes of $E$. coli like st 1 and stx 2 for shiga toxin-producing E. coli (STEC) and enterohemorrhagic E. coli (EHEC), esc $\mathrm{V}$ for enteropathogenic E. coli (EPEC) and $i n v \mathrm{E}$ for enteroinvasive E. coli (EIEC).

\section{Materials and Methods}

Sample collection and preparation

Multiple vel-puri, fuchka, water and salad materials were collected in labeled sterile zip lock bag from different street food vendors around the Dhaka city in Bangladesh with a regular time interval. All the samples were brought immediately to the laboratory for processing. Samples were either directly dissolved or were homogenized in sterile saline solution before culture. Occasionally, samples were resuscitated in sterile peptone water. All the water samples were first centrifuged at $10000 \mathrm{rpm}$ for 10

*Corresponding author:

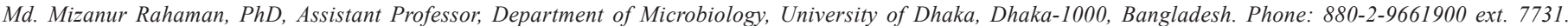
Fax: 880-2-9667222. Email: razu002@gmail.com 
minutes twice with sterile physiological saline and the pellets were collected for culture.

\section{Isolation of bacterial strains}

All samples were inoculated on MacConkey agar plates and were incubated at $37^{\circ} \mathrm{C}$ for 18 hours. Pure colonies on the MacConkey agar plates were randomly selected based on their characteristics colony color and texture, and were further streaked on EMB agar plates to primarily sort out enteric bacteria. Isolates producing characteristics metallic green sheen colony on EMB agar plates were considered for further experimentation and were preserved in $20 \%$ glycerol at $-80{ }^{\circ} \mathrm{C}$.

\section{Biochemical characterization of the isolates}

Isolates were characterized by their response to different biochemical tests that includes Kligler Iron agar (KIA), Motility Indole Urease (MIU), Methyl-Red (MR), Voges-Proskauer(VP), Triple Sugar Iron (TSI), citrate utilization, catalase and oxidase tests ${ }^{12}$.

\section{Molecular characterization of the isolates}

Randomly amplified polymorphic DNA (RAPD) method, amplified rDNA restriction analysis (ARDRA) method, and partial sequencing of $16 \mathrm{~S}$ rDNA gene of the isolates were performed for further characterization. For RAPD, PCR reactions were carried out in $25-\mu \mathrm{L}$ volumes containing: $12.5 \mu \mathrm{l}$ of $2 \mathrm{X}$ mastermix, $1 \mu 1$ of 10 pmol primer (sequence: 52 GCGATCCCCA-32 $)^{13}, 3 \mu$ template DNA and nuclease-free water up to the volume. Amplification was performed using PCR thermal cycler with condition: initial denaturation at $95^{\circ} \mathrm{C}$ for 5 min, followed by 35 cycles of $1 \mathrm{~min}$ at $94{ }^{\circ} \mathrm{C}, 1 \mathrm{~min}$ at $40^{\circ} \mathrm{C}$, and $2 \mathrm{~min}$ at $72{ }^{\circ} \mathrm{C}$ with a final extension of $10 \mathrm{~min}$ at $72^{\circ} \mathrm{C}$. After amplification, PCR product was subjected to agarose gel electrophoresis and visualized under UV-transilluminator. 16s rDNA amplicons were generated by PCR was accomplished using forward primer: 52 -AGAGTTTGATCMATGGCTCAG-32 and reverse primer: 52 -GGTTACCTTGTTACGACTT-32 primers $^{14}$. Reaction conditions of thermal cycler were: initial denaturation at $95{ }^{\circ} \mathrm{C}$ for $5 \mathrm{~min}$, followed by 35 cycles of $1 \mathrm{~min}$ at $94{ }^{\circ} \mathrm{C}, 1$ $\min$ at $58^{\circ} \mathrm{C}$, and $1 \mathrm{~min}$ at $72^{\circ} \mathrm{C}$ with a final extension of $10 \mathrm{~min}$ at $72^{\circ} \mathrm{C}$. For ARDRA, a single restriction enzyme AluI (Thermo Fisher Scientific, USA) was used for the digestion of $16 \mathrm{~s}$ rDNA amplicons overnight at $37^{\circ} \mathrm{C}$. After digestion, the products were resolved in $1.5 \%$ agarose gel. For partial sequencing of $16 \mathrm{~S}$ rDNA gene, the 16s rDNA amplicons were purified with the Wizard PCR SV Gel and PCR Clean-Up System kit (Promega, USA) according to the manual instruction. The purified $\mathrm{PCR}$ products were sequenced by automated cycle sequencing from DNA sequencing lab of First BASE Laboratories, Malaysia.

\section{Bioinformatic analysis}

Sequences were assembled in SeqMan Genome Assembler and the complete sequences were blasted at NCBI to identify individual strains. Phylogenetic and molecular evolutionary analyses were conducted using the MEGA version 7.0 software package. Trees were generated using neighbor-joining algorithm with 1000 bootstrap replication. A Mycobacterium spp. sequences was used as an out-group.

\section{Detection of different virulent genes}

Four different virulent genes (stx1, stx2, esc $\mathrm{V}$, and $i n v \mathrm{E}$ ) was detected by PCR using the primers listed in Table 1 . The reaction conditions were optimized by slightly modifying a protocol described previously ${ }^{15}$. The target genes were amplified individually.

\section{Antimicrobial susceptibility tests}

Antimicrobial susceptibility of the isolated strains was determined by standard Kirby-Bauer disk diffusion method ${ }^{16}$. The antibiotics tested were ciprofloxacin, amoxicillin, nitrofurantoin, trimethoprim, azithromycin and gentamicin (Oxoid, UK). Briefly, a colony of individual strain was transferred into $5 \mathrm{ml}$ of nutrient broth and was allowed to grow at $37^{\circ} \mathrm{C}$ for $8 \mathrm{~h}$ with shaking to obtain young culture adjusted to McFarland 0.5 standard $\left(2 \times 10^{8}\right.$ $\mathrm{cfu} / \mathrm{ml}$ ). A sterile swab dipped into this standardized suspension was streaked evenly in two directions over the entire surface of a Muller-Hinton agar (Oxoid, UK) plate to obtain uniform lawn of bacterial culture. The antibiotic disks were then applied to the inoculated plates with sterile forceps and were incubated at 37 ${ }^{\circ} \mathrm{C}$ for $24 \mathrm{~h}$. Then, the diameters of the zones of complete inhibition were measured using a scale. The results were interpreted as mentioned by Clinical and Laboratory Standards Institute (CLSI) standard guidelines ${ }^{17}$.

Table 1. Primers used for PCR amplification of different virulence genes.

\begin{tabular}{|c|c|c|c|c|}
\hline Target & Primer & Primer sequence $(52-32)$ & $\mathrm{T}_{\mathrm{m}}\left({ }^{\circ} \mathrm{C}\right)$ & Amplicon (bp) \\
\hline \multirow[t]{2}{*}{ stx 1} & stx1 F & AGTTAATGTGGTGGCGAAGG & 60 & 347 \\
\hline & stx $1 \mathrm{R}$ & CACCAGACAATGTAACCGC & & \\
\hline & stx2 R & CGTCATCGTATACACAGGAG & & \\
\hline$i n v \mathrm{E}$ & invE F & GCAGGAGCAGATCTTGAAG & 58 & 208 \\
\hline & escV R & CСТTTTACAAACTTCATCGCC & & \\
\hline
\end{tabular}




\section{Results}

\section{Basic biochemical characteristics of the isolated strains}

23 individual Gram negative bacterial strains producing metallic green sheen on EMB agar were isolated from the studied street food samples. Colonies of these strains were circular, raised or flat and dry or gummy. They produced gas and acidic reaction in both butt and slant of KIA. Also, they were motile and positive for urease, VP, citrate and catalase tests, but negative for $\mathrm{H}_{2} \mathrm{~S}$, indole, MR and oxidase tests. These data indicated that these strains were enteric bacterial strains, from which 16 isolates were Escherichia coli and the remaining 7 isolates were Enterobacter spp.

\section{Molecular characteristics of the isolated strains}

10 different RAPD patterns were identified in these isolated strains. Figure 1 represents a typical photograph showing six different RAPD patterns. Such observation indicates that these enteric bacterial strains are possibly different from each other. To further validate this and to genotype these strains, ARDRA was performed. Figure 2 represents a typical ARDRA pattern of the isolated strains. ARDRA showed that these strains can be grouped in two types: one group of 7 isolates showing three bands of about $100 \mathrm{bp}, 250 \mathrm{bp}$ and $550 \mathrm{bp}$, and the other group of 16 isolates showing two bands of about $100 \mathrm{bp}$ and $250 \mathrm{bp}$. 16S rDNA sequencing of these strains confirms that the isolates showing three bands in ARDRA were actually Enterobacter spp. ( 7 isolates) and the remaining isolates were E. coli (16 isolates). Figure 3 represents a typical phylogenetic tree showing clustering of Enterobacter spp. E. coli.

\section{Presence of different virulence genes in the E. coli isolates}

Among the $16 E$. coli isolates, 5 were stx 1 positive, 4 were stx 2 positive and the remaining 7 were esc $\mathrm{V}$ positive (Figure 4). All of the $E$. coli isolates were $i n v \mathrm{E}$ negative (data not shown). So among the different pathotypes of $E$. coli, this study identified 9 shiga toxin-producing $E$. coli and enterohemorrhagic $E$. coli (stx 1 and stx2 positive), and seven enteropathogenic E. coli (esc V positive) in the street food samples.

\section{Antibacterial resistance}

Antibacterial resistance analysis of all the isolated bacteria revealed that most of the isolates were resistant to azithromycin $(72 \%)$ and amoxicillin (64\%). However most of them are sensitive to ciprofloxacin (76\%), nitrofurantoin (84\%), trimethoprim (72\%) and gentamycin $(80 \%)$ respectively (Figure 5$)$.

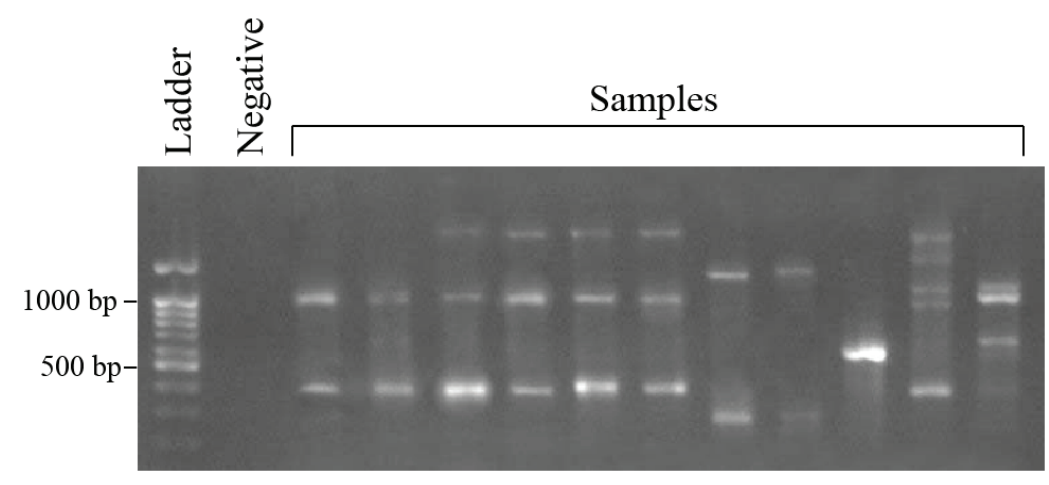

Figure 1. RAPD analysis of the isolated strains. Six different RAPD patterns are shown here.

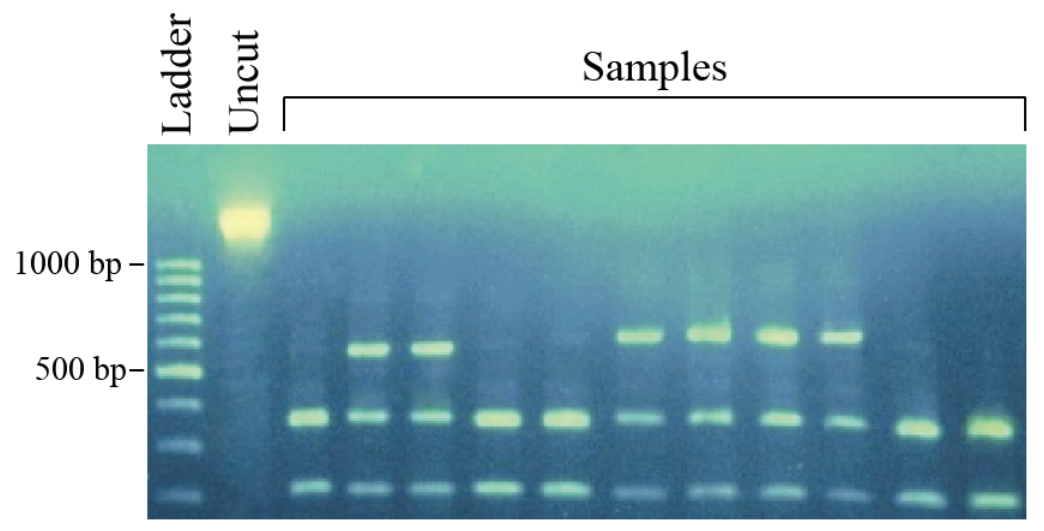

Figure 2. ARDRA of the isolated strains. The isolated strains can be grouped in two types based on ARDRA pattern. 


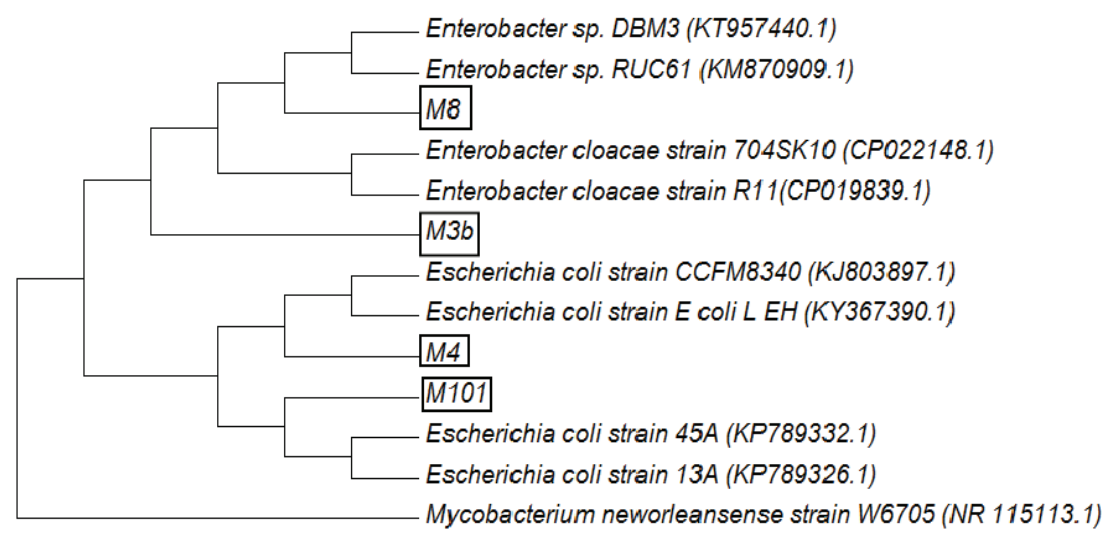

Figure 3. Phylogenetic tree constructed from partial16S rDNA sequences of the isolated strains. Two strains, namely M8 and M3b clusters with Enterobacter spp., and M4 and M101 clusters with E. coli. Mycobacterium neworleansense was used as an out-group organism.

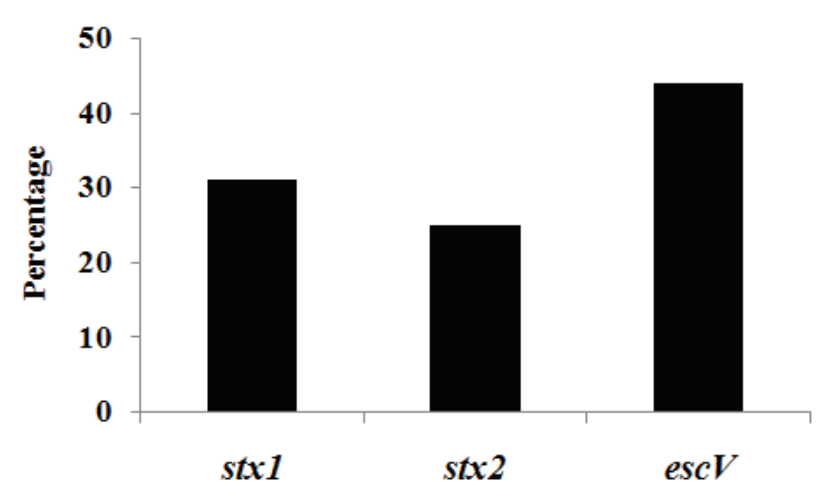

Figure 4. Percentage of different virulence genes found in the isolates. Most of the isolates carry escV gene.

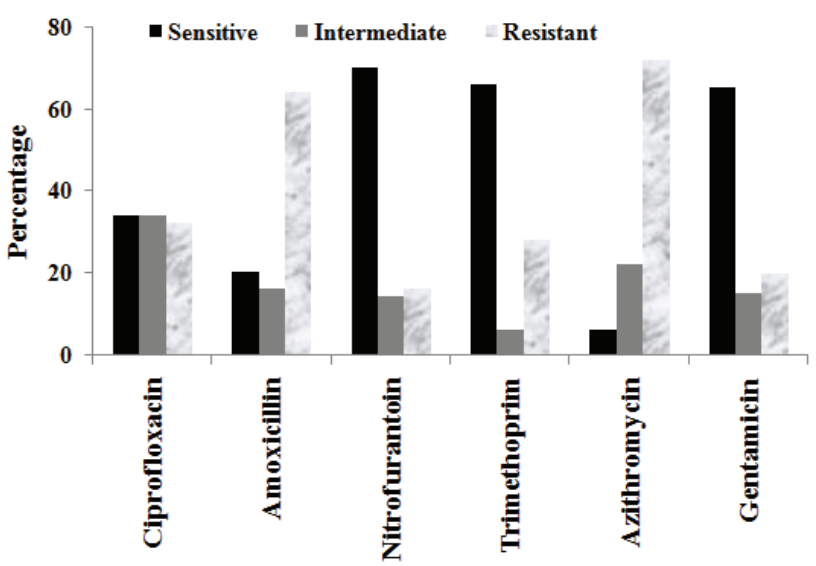

Figure 5. Antibiotic sensitivity of the 23 isolates against common antibiotics used for enteric bacterial infections.

\section{Discussion}

Disease outbreaks associated with food borne diarrheagenic $E$. coli are frequently reported in the developed countries due to the existence of a comprehensive surveillance system ${ }^{18}$. Although the socioeconomic condition of Bangladesh indulges vary high prevalence of pathogenic bacteria in the food chain, the current surveillance system is poorly defined ${ }^{8}$. Street food vending is very common and popular in busiest city Dhaka in Bangladesh ${ }^{19}$. Most people like these street foods both for its cheap price as well as for its mouth-watering taste. But a good number of investigations reported that street foods are dangerous, especially for enteric bacteria ${ }^{8,20}$. Hence, this study was carried out to comprehend the virulence potential as well as multidrug resistance status of the enteric bacteria in the street food items in Dhaka city.

From different street foods, 23 enteric bacteria like isolates on selective agar were analyzed using molecular techniques like ARDRA. This molecular analysis made it convenient to conduct the conventional biochemical tests as well as reduced the load of $16 \mathrm{~S}$ rDNA sequence analysis for all isolates. ARDRA grouping revealed 2 different patterns from all the isolates (Figure 2) which later presumptively confirmed as E. coli and Enterobacter spp. by conventional biochemical tests. In this study, RAPD typing was also accomplished which further differentiated two ARDRA group isolates into 10 different patterns (Figure 1). Isolates were selected for sequencing based on 16S rDNA gene from 2 different ARDRA groups with different RAPD types to interpret the close relative species. The $16 \mathrm{~S}$ rDNA sequencing and phylogenetic analysis further confirmed the identification of the bacteria from two different ARDRA groups as E. coli and Enterobacter spp (Figure 3). Isolates from the same ARDRA group with different RAPD type showed the same genus of bacteria.

To characterize the virulence traits of the identified $E$. coli strain, a PCR based assay was employed for in vitro determination of the stx 1 and stx 2 genes encoding shiga-like toxin ( $\mathrm{Stx}), e s c \mathrm{~V}$ gene encoding EscV protein of Type III secretion systems (T3SSs) and $i n v \mathrm{E}$ gene encoding InvE protein for invasion which is atypical for enteroinvasive Escherichia coli. Determination of the stx 1 andst 2 confirmed the presence of diarrhoeagenic $E$. coli (especially STEC and EHEC) strains in the street food 
samples. Detection of esc V gene confirmed the presence of enteropathogenic E.coli (EPEC) in the food samples (Figure 4). No band for invE confirmed the absence of EIEC strains in the food samples. Therefore, the pathogenic E. coli strains found in this study belong to three different pathotypes: STEC, EHEC and EPEC. EPEC (43\%) represents the most frequent pathotype in the street food samples followed by STEC (17\%). The prevalence of $s t x 1$ gene was $17 \%$ among the strains tested whereas st 2 gene was $55 \%$. st 2 is more associated than st 1 with the EHEC strains that cause hemolytic-uremic syndrome. Results of the prevalence of potential pathogenic $E$. coli strains in the street food samples could be explained by the fact that these foods might be contaminated by fecal coliform. Another reasonable fact could be that most of the street food items were sampled near hospital area where the foods might get contaminated with clinical sewage. In addition, most of the homeless people living in Dhaka city without sanitary latrines, usually defecate in the roadside through which the vending items might get contaminated.

Irrational use of antibiotics has already made the situation worse in Bangladesh. As anticipated, high resistance against commonly used antibiotics was found. Many of the isolates studied here were found multi-drug resistant. Most people in Bangladesh use antibiotic indiscriminately even in case of viral infection. As a result multidrug resistant bacteria thrived in the environment. Highest resistance was observed with the amoxicillin and azithromycin (Figure 5) and moderately resistance to other antibiotics. So it appears that none of the drugs could be prescribed exclusively that would be effective against all the tested pathogens.

\section{Conclusion}

This study successfully identified pathogenic Escherichia coli with some dangerous virulence traits from different street food samples and also found them resistant to commonly used antibiotics. Hence, this is really an alarming situation putting a huge threat to the public health of Bangladesh. One of our previous studies also reported the high load of enteric bacteria in the hands of street food vendors ${ }^{10}$. Therefore, both the street foods and the personnel involving street food vending could be an exclusive reason to cause enteric diseases to the consumers ${ }^{7-}$ 9 . To overcome such situation, proper regulation and monitoring in street food vending activities are warranted. Food handlers and street food vendors need to train about personal hygiene and microbiological quality environment for food preparation.

\section{Conflict of interest}

The authors declare no conflict of interest.

\section{Acknowledgement}

We acknowledge the University Grants commission of Bangladesh and Ministry of Science and Technology, Peoples Republic of Bangladesh for funding this research. We thank
Professor Dr. Sabita Rezwana Rahman, Professor Dr. Majibur Rahman and Professor Dr. Anwar Hossain, Department of Microbiology, University of Dhaka for their kind support with the lab space and instruments.

\section{References}

1. Rabbani GH and Greenough WB. 1999. Food as a vehicle of transmission of cholera. J. Diarrhoeal Dis. Res. 17: 1-9.

2. Abdullah WZW, Mackey BM and Karatzas KAG. 2017. High Phenotypic Variability among Representative Strains of Common Salmonella enterica Serovars with Possible Implications for Food Safety. J. Food Prot. 78: 93-104.

3. Borchers A, Teuber SS, Keen CL and Gershwin ME. 2010. Food safety. Clin. Rev. Allergy Immunol. 39: 95-141.

4. Baker KK, O'Reilly CE, Levine MM, Kotloff KL, Nataro JP, Ayers TL, Farag TH, Nasrin D, Blackwelder WC, Wu Y, Alonso PL, Omore R, Faruque AS, Das SK, Ahmed S, Saha D, Sow SO, Sur D, Zaidi AK, Quadri F and Mintz ED. 2016. Sanitation and Hygiene-Specific Risk Factors for Moderate-to-Severe Diarrhea in Young Children in the Global Enteric Multicenter Study, 2007-2011: Case-Control Study. PLoS Med. 13: e1002010

5. Ma L, Chen H, Yan H, Yang L and Wu L. 2017. Multiple attribute decision making model and application to food safety risk evaluation. PLoS One. 12: e0189835.

6. Greksa LP, Islam A, Okamoto R and Omori K. 2017. Dietary Patterns and Dietary Adequacy of Street Children in Dhaka, Bangladesh. Eco.l Food Nutr. 56: 479-492.

7. Islam S, Nasrin N, Rizwan F, Nahar L, Bhowmik A, Esha SA, Talukder KA, Akter M, Roy A and Ahmed M. 2015. Microbial Contamination of Street Vended Foods from a University Campus in Bangladesh. S. Asian J. Trop. Med. Public Health. 46: 480-5.

8. Al-Mamun M, Rahman SM and Turin TC. 2013. Knowledge and awareness of children's food safety among school-based street food vendors in Dhaka, Bangladesh. Foodborne Pathog. Dis. 10: 323-30.

9. Al-Mamun M, Rahman SM and Turin TC. 2013. Microbiological quality of selected street food items vended by school-based street food vendors in Dhaka, Bangladesh. Int. J. Food Microbiol. 166: 413-8.

10. Yaici L, Haenni M, Metayer V, Saras E, Mesbah Zekar F, Ayad M, Touati A and Madec JY. 2017. Spread of ESBL/AmpC-producing Escherichia coli and Klebsiella pneumoniae in the community through ready-to-eat sandwiches in Algeria. Int. J. Food Microbiol. 245: 66-72.

11. Islam MA, Mondol AS, Azmi IJ, de Boer E, Beumer RR, Zwietering MH, Heuvelink AE and Talukder KA. 2010. Occurrence and characterization of Shiga toxin-producing Escherichia coli in raw meat, raw milk, and street vended juices in Bangladesh. Foodborne Pathog. Dis. 7: 1381-5.

12. Farmer JJ, Davis BR, Hickman-Brenner FW, McWhorter A, HuntleyCarter GP, Asbury MA, Riddle C, et al. 1985. Biochemical identification of new species and biogroups of Enterobacteriaceae isolated from clinical specimens. J. Clin. Microbiol. 21: 46-76.

13. Marialouis XA and Santhanam A. 2016. Antibiotic Resistance, RAPDPCR Typing of Multiple Drug Resistant Strains of Escherichia coli From Urinary Tract Infection (UTI). J. Clin. Diagn. Res. 10: 5-9.

14. Vaneechoutte M, Rossau R, Vos DP, Gillis M, Janssens D, Paepe N, De Rouck A, Fiers T, Claeys G and Kersters K. 1992. Rapid identification of bacteria of the Comamonadaceae with amplified ribosomal DNArestriction analysis (ARDRA). FEMS Microbiol. Lett. 72: 227-33.

15. Muller D, Hagedorn P, Brast S, Heusipp G, Bielaszewska M, Friedrich AW, Karch H and Schmidt MA. 2006. Rapid identification and 
differentiation of clinical isolates of enteropathogenic Escherichia coli (EPEC), atypical EPEC, and Shiga toxin-producing Escherichia coli by a one-step multiplex PCR method. J. Clin. Microbiol. 44: 2626-9.

16. Bauer AW, Kirby WM, Sherris JC and Turck M. 1966. Antibiotic susceptibility testing by a standardized single disk method. Am. J. Clin. Pathol. 45: 493-6.

17. Hindler JF and Stelling J. 2007. Analysis and presentation of cumulative antibiograms: a new consensus guideline from the Clinical and Laboratory Standards Institute. Clin. Infect. Dis. 44: 867-73.
18. Ao TT, Rahman M, Haque F, Chakraborty A, Hossain MJ, Haider S, Alamgir AS, Sobel J, Luby SP and Gurley ES. 2016. Low-Cost National Media-Based Surveillance System for Public Health Events, Bangladesh. Emerg. Infect. Dis. 22: 720-2.

19. Khairuzzaman M, Chowdhury FM, Zaman S, Al Mamun A and Bari ML. 2014. Food Safety Challenges towards Safe, Healthy, and Nutritious Street Foods in Bangladesh. Int. J. Food Sci. 2014: 483519.

20. Hassan MM, Chakrabarty RP, Siddique MA and Rahaman MM. 2017. Prevalence of antibiotic resistant enteric bacteria in the hands of street food vendors in Dhaka city. Bangladesh J. Microbiol. 34: 25-29. 